\title{
Effect of mango seed kernel extract on the adipogenesis in 3T3-L1 adipocytes and in rats fed a high fat diet
}

\author{
Mai Kobayashi ${ }^{1}$, Isao Matsui-Yuasa ${ }^{1}$, Maiko Fukuda-Shimizu ${ }^{2}$, Yoshinobu Mandai ${ }^{2}$, \\ Masaki Tabuchi ${ }^{3}$, Hiroshi Munakata ${ }^{3}$, Akiko Kojima-Yuasa $^{1^{*}}$ \\ ${ }^{1}$ Department of Food and Human Health Sciences, Graduate School of Human Life Science, Osaka City University, Osaka, Japan \\ *Corresponding Author: kojima@life.osaka-cu.ac.jp \\ ${ }^{2}$ Nitta Gelatin Inc., Yao, Japan \\ ${ }^{3}$ Department of Biochemistry, Kinki University Medical School, Osaka-Sayama, Japan
}

Received 22 June 2013; revised 15 July 2013; accepted 26 July 2013

Copyright (C) 2013 Mai Kobayashi et al. This is an open access article distributed under the Creative Commons Attribution License, which permits unrestricted use, distribution, and reproduction in any medium, provided the original work is properly cited.

\begin{abstract}
Mangoes (Mangifera indica L.) are one of the most important tropical foods. The seed is one of the main by-products of mango processing. Therefore, it is important to find an economically viable use for this waste (e.g., as a food additive or supplement with high nutraceutical value). We investigated the anti-obesity effects of mango seed kernel extract with hot water (MSKE-W) in 3T3-L1 adipocytes and in a high fat diet (HFD)-induced obesity rat model. MSKE-W caused a significant decrease in the activity of glycerol 2-phosphate dehydrogenase in 3T3-L1 adipocytes without eliciting cell cytotoxicity and inhibited cellular lipid accumulation through down-regulation of transcription factors such as PPARY and C/EBPa. In the animal model, rats fed an HFD containing 1\% MSKE-W gained less weight than rats fed an HFD alone. The visceral fat mass in rats fed an HFD containing 1\% MSKE-W tended to be lower than that in rats fed an HFD alone. Furthermore, histological examination of rat livers from an HFD showed steatohepatitis. However, rats on an HFD containning 1\% MSKE-W showed no histopathological changes in liver tissue. Our results indicate that MSKE-W influences anti-obesity effects, both in vitro and in vivo, and suggest that MSKE-W provides a novel preventive potential against obesity.
\end{abstract}

Keywords: Mago Seed Kernel; Glycerol 2-Phosphate Dehydrogenase (GPDH); Peroxisome
Proliferator-Activated Receptor $y$ (PPAR $y$ ); High Fat Diet-Induced Obesity Rat Model; 3T3-L1 Adipocytes

\section{INTRODUCTION}

Adipose tissue, as a metabolic and endocrine organ, plays critical roles in the regulation of energy balance, lipid metabolism and insulin action [1]. Therefore, obesity is a major public health concern in many countries. Obesity is characterized by excessive fat deposition, which is associated with morphological and functional changes in adipocytes [2]. Adipocytes have been emerging as a potential pharmacological target for obesity, diabetes and cardiovascular disease [3]. Adipogenesis is a process beginning with fibroblast-like preadipocytes that leads to eventual mature adipocytes, and it is regulated by two key families of adipogenic transcription factors, CCAAT/enhancer-binding proteins (C/EBPs) and peroxisome proliferator-activated receptor $\gamma(\operatorname{PPAR} \gamma)$. Both of these factors are necessary to promote the terminal or mature adipocyte phenotype. In response to hormonal stimuli of adipogenesis, $\mathrm{C} / \mathrm{EBP} \beta$ is rapidly and transiently induced, followed by the expression of $\operatorname{PPAR} \gamma$ and $\mathrm{C} / \mathrm{EBP} \alpha$ [4]. PPAR $\gamma$ and $\mathrm{C} / \mathrm{EBP} \alpha$ then act synergistically to induce the expression of genes that are necessary for the generation and maintenance of the adipogenic phenotype such as lipid accumulation [5].

Mangoes (Mangifera indica L.) are one of the most popular and economically important tropical fruits marketed worldwide. Mangoes are either consumed fresh or processed into a wide range of products such as purees, nectars, chutneys, fruit slices, bars and powders. During processing, the peels and kernels are usually removed, which creates a large amount of by-product. Although 
these byproducts are often considered waste, more recent studies have shown that the peels and kernels are promising sources of valuable components, such as peel pectin [6], kernel fat [7] and phenolic compounds [6,8]. The kernels have also been pharmacologically documented to have antioxidant, anti-tyrosinase, anti-inflammatory and hepatoprotective activities $[9,10]$ as well as anti-enzymatic activities against snake venom $[11,12]$.

However, the inhibitory effect of mango seed kernel extract (MSKE) on obesity is unknown. Therefore, this study examined the anti-obesity potential of MSKE on adipogenesis in 3T3-L1 adipocytes and high fat-fed rats.

\section{MATERIALS AND METHODS}

\subsection{Materials}

Oil red O, 3-isobutyl-1-methylxanthine (IBMX), dexamethasone (DEX) and insulin (INS) were purchased from Wako Pure Chemicals Industries, Ltd. (Osaka, Japan). Anti-PPAR $\gamma$, anti-C/EBP $\alpha$ and anti- $\beta$-actin antibodies were purchased from Santa Cruz Biotechnology Inc. (Santa Cruz, CA, USA). Fetal bovine serum (FBS) was purchased from Nichirei Bioscience Inc. (Tokyo, Japan). Other chemicals used in this study were special grade commercial products.

\subsection{Preparation of MSKE-W}

Dried mango seed kernels were milled, and the powder was extracted with distilled water at $60^{\circ} \mathrm{C}$ for 3 hours. MSKE-W was freeze dried and solved in dimethylsulfoxide (DMSO) for experiments.

\subsection{Animals and Diet}

Four-week-old male Sprague-Dawley rats (Japan SLC, Shizuoka, Japan) were housed in a temperature-controlled room at $23^{\circ} \mathrm{C} \pm 1{ }^{\circ} \mathrm{C}$ with a ratio of 12 hours light/12 hours darkness, and they were fed a commercial diet (LabMR) for 11 days. The rats were randomly divided into 4 groups $(n=6)$ as follows: normal-diet (ND), ND supplemented with $1.0 \%$ MSKE-W, high fat-diet (HFD) and HFD supplemented with 1.0\% MSKE-W. The HFD contained $240 \mathrm{~g}$ fat $/ \mathrm{kg}$ (170 g lard plus $70 \mathrm{~g}$ soy bean oil), as shown in Table 1 . This study adhered to the Guide for the Care and Use of Laboratory Animals based on the guidelines for animal experimentation at Osaka City University in Osaka, Japan.

\subsection{Histologic Procedure}

Samples of liver and visceral fat were collected from each rat, fixed in $10 \%$ buffered formalin fixative and dehydrated in a graded series of alcohol. Following xylene treatment, specimens were embedded in paraffin blocks and cut into $5 \mu \mathrm{M}$ sections. Consecutive sections
Table 1. Composition of diets.

\begin{tabular}{ccccc}
\hline Components (g) & ND & $\begin{array}{c}\text { ND }+1.0 \% \\
\text { MSKE-W }\end{array}$ & HFD & $\begin{array}{c}\text { HFD + 1.0\% } \\
\text { MSEK-W }\end{array}$ \\
\hline Corn starch & 397.486 & 396.986 & 269.986 & 269.486 \\
Casein & 200.000 & 200.000 & 200.000 & 200.000 \\
Lard & 0.000 & 0.000 & 170.000 & 170.000 \\
a-Corn starch & 132.000 & 132.000 & 89.500 & 89.500 \\
Sucrose & 100.000 & 100.000 & 100.000 & 100.000 \\
Soybean oil & 70.000 & 70.000 & 70.000 & 70.000 \\
Cellulose powder & 50.000 & 50.000 & 50.000 & 50.000 \\
AIN-93G Mineral Mix & 35.000 & 35.000 & 35.000 & 35.000 \\
AIN-93 Vitamin Mix & 10.000 & 10.000 & 10.000 & 10.000 \\
L-Cystine & 3.000 & 3.000 & 3.000 & 3.000 \\
Choline bitartrate & 2.500 & 2.500 & 2.500 & 2.500 \\
Tert-Butylhydroquinone & 0.014 & 0.014 & 0.014 & 0.014 \\
MSKE-W & 0.000 & 10.000 & 0.000 & 10.000 \\
Total & 1000.000 & 1000.000 & 1000.000 & 1000.000 \\
\hline
\end{tabular}

of liver and visceral adipose tissue were stained with hematoxylin and eosin (HE).

\subsection{Cell Culture and Adipocyte Differentiation}

The mouse embryo 3T3-L1 cells were obtained from the Human Science Research Resource Bank (HSRRB, Osaka, Japan). The 3T3-L1 preadipocytes were incubated in Dulbecco's Modified Eagle's Medium (DMEM) containing $10 \% \mathrm{FBS}$ and $100 \mathrm{U} / \mathrm{ml}$ penicillin-streptomycin. Differentiation into the adipocyte form was induced by incubating $10^{5}$ cells in DMEM containing $10 \%$ FBS, $0.5 \mathrm{mM}$ IBMX, $0.25 \mu \mathrm{M}$ DEX and $0.2 \mu \mathrm{M}$ INS for 2 days. The cells were then incubated for an additional 2 days in DMEM containing 10\% FBS and $0.2 \mu \mathrm{M}$ INS. The medium was then changed to a normal culture medium and was freshly replaced every 2 days. The cells were harvested 8 days after the initiation of differentiation. Cell culture conditions were maintained at $37^{\circ} \mathrm{C}$ in a humidified $5 \% \mathrm{CO}_{2}$ incubator.

\subsection{Neutral Red Assay}

Cell viability was determined by neutral red uptake assay based on lysosomal uptake of neutral red [13]. Following specified incubations with test agents, neutral red solution $(0.25 \mathrm{mg} / \mathrm{ml})$ was added to the cell cultures at a final concentration of $50 \mu \mathrm{g} / \mathrm{ml}$. After incubation at $37^{\circ} \mathrm{C}$ for 2 hours, cells were rinsed twice with a mixture of $1 \%$ (v/v) formaldehyde, 1\% (v/v) calcium chloride, and 98\% $(\mathrm{v} / \mathrm{v})$ distilled water. Subsequently, $1 \mathrm{ml}$ of destaining buffer consisting of $1 \%(\mathrm{v} / \mathrm{v})$ acetic acid, 50\% (v/v) 
ethanol, and $49 \%(\mathrm{v} / \mathrm{v})$ distilled water was added to the cells and the culture plates were left for 30 minutes. Lysosomal uptake of neutral red was determined spectrophotometrically at $540 \mathrm{~nm}$ to quantify neutral red uptake $[14,15]$. Viability was expressed as (A540-treated cells/ A540 of appropriate control) $\times 100 \%$ after correction for background absorbance.

\subsection{Oil Red O Staining}

Intercellular lipid accumulation was measured by Oil Red $\mathrm{O}$ staining. The Oil Red $\mathrm{O}$ working solution was prepared as previously described $[15,16]$. Undifferentiated 3T3-L1 preadipocytes were induced to differentiate into adipocytes as described above. Cells were incubated with various concentrations of MSKE-E or MSKE-W for the differentiation periods. Cells were washed twice with phosphate buffered saline (PBS) and then fixed for 30 seconds with $70 \%$ ethanol. The cultures were then incubated for 2 hours with a saturated solution of Oil Red $\mathrm{O}$ in $99 \%$ isopropyl alcohol, rinsed for 3 seconds in 50\% ethanol, and washed twice with deionized water.

\subsection{Glycerol 2-Phosphate Dehydrogenase (GPDH) Activity}

The 3T3-L1 adipocytes were harvested 5 days after the initiation of differentiation with various concentration of MSKE-W. Cells were carefully washed twice with icecold PBS and collected with a scraper into $300 \mu \mathrm{l}$ of 100 $\mathrm{mM}$ triethanolamine $/ \mathrm{HCl}$ buffer $(\mathrm{pH} 7.5)$ and $2.5 \mathrm{mM}$ EDTA. Harvested cells were sonicated with 25 ultrasonic bursts of 10 seconds each in a DU-250 Bioruptor (Tosho Denki Co. Ltd., Japan) with a maximum output power of $250 \mathrm{~W}$. Samples were chilled on ice between sonication bursts. After centrifugation at $13000 \times g$ for 5 minutes at $4^{\circ} \mathrm{C}$, the supernatant was assayed for GPDH activity according to the Wise and Green method [17]. GPDH activity was measured under zero-order kinetics and optimal substrate and cofactor conditions at $25^{\circ} \mathrm{C}$ for 180 seconds in a DU 530 spectrophotometer (Beckman Coulter). The standard reaction mixture contained 100 $\mathrm{mM}$ triethanolamine/ $\mathrm{HCl}$ buffer ( $\mathrm{pH} 7.5), 2.5 \mathrm{mM}$ EDTA, $0.1 \mathrm{mM} / 2$-mercaptoethanol, and $0.12 \mathrm{mM} \mathrm{NADH}$. The reaction was initiated by the addition of $0.2 \mathrm{mM}$ dihydroxyacetone phosphate, and the rate of NADH oxidation was measured by the change in absorbance at 340 $\mathrm{nm}$ for 60 seconds. Enzyme activity (\%) was expressed as a ratio of the experimental condition relative to the control (which was set at $100 \%$ activity).

\subsection{Western Blot Analysis}

Cells were harvested at either 2 or 5 days after initiation of differentiation with $0-50 \mu \mathrm{g} / \mathrm{ml} \mathrm{MSKE-W,}$ washed twice in PBS and dissolved for 30 minutes with lysis buffer $(50 \mathrm{mM} \mathrm{NaCl}, 50 \mathrm{mM}$ Tris $(\mathrm{pH} 7.2), 1 \mathrm{mM}$ EDTA, 0.5\% sodium deoxycholate, 1\% Nonidet P-40, 1 $\mathrm{mM}$ sodium vanadate, $1 \mathrm{mM} \mathrm{NaF}, 20 \mu \mathrm{g} / \mathrm{ml}$ aprotinin, 50 $\mu \mathrm{g} / \mathrm{ml}$ leupeptin, $10 \mu \mathrm{g} / \mathrm{ml}$ pepstatin A and $100 \mu \mathrm{g} / \mathrm{ml}$ phenylmethylsulfonyl fluoride). Finally, the solution was centrifuged at $2000 \times g$ for 20 minutes at $4^{\circ} \mathrm{C}$. The supernatant was collected, and protein concentrations were determined by the Bradford method. Equal amounts of protein were fractionated on 10\% SDS-PAGE gels and transferred to $0.45 \mu \mathrm{M}$ PVDF (Hybond, Amersham Pharmacia Biotech). After blotting overnight in $0.1 \%$ Tween-20 and 5\% non-fat dry milk (in PBS), blots were incubated with anti-PPAR $\gamma$ or anti-C/EBP $\alpha$ antibody for 1 hour at room temperature. After washing, the membrane was incubated with 1:500 diluted biotinylated mouse IgG or rabbit IgG for 1 hour at room temperature. The membrane was washed three times and incubated with diluted (1:500) horseradish peroxidase-coupled streptavidin for 1 hour at room temperature. After several washing steps, the color reaction was developed with 3,3'-diaminobenzidin tetrahydrochloride (DAB). Densitometry analysis of the protein bands was then performed with Scion Image software.

\subsection{Statistical Analysis}

Data are expressed as the mean \pm standard deviation. The significant differences of assay values were evaluated by ANOVA followed by Tukey multiple tests. A value of $p<0.05$ was used to indicate statistical significance.

\section{RESULTS}

\subsection{Effect of MSKE-W on Cell Viability}

Cell viability of 3T3-L1 preadipocytes was examined with various concentrations of mango seed kernel extract with hot water (MSKE-W) by neutral red assay. As shown in Figure 1, none of these fractions affected cell viability in 3T3-L1 preadipocytes, showing that these concentrations of MSKE-W are not cytotoxic in 3T3-L1 preadipocytes.

\subsection{Effect of MSKE-W on Lipid Accumulation and GPDH Activity}

The effect of MSKE-W on intracellular lipid accumulation was examined by Oil Red $\mathrm{O}$ staining. On the 5th day of incubation, mature 3T3-L1 adipocytes accumulated many Oil Red $\mathrm{O}$ stained materials, as indicated by large intracellular droplets. Most control cells had accumulated lipid droplets (Figure 2(a), (b)). However, the treatment of MSKE-W dose-dependently decreased the accumulation of lipid droplets, showing that MSKE-W inhibit the accumulation of intracellular triglycerides in 


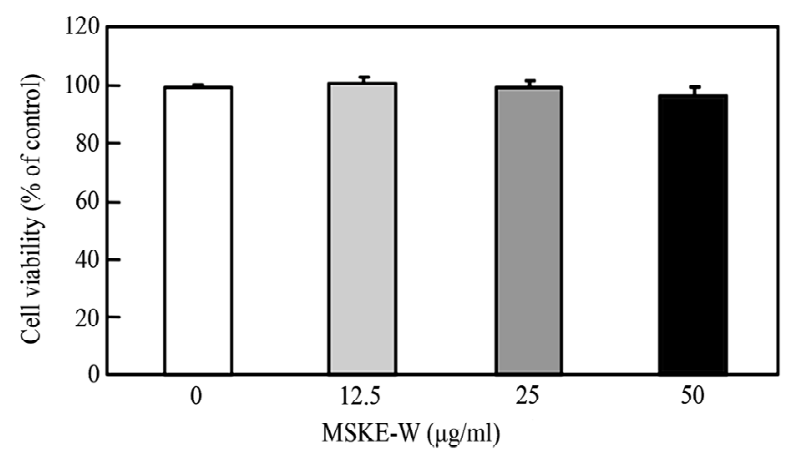

Figure 1. Effect of MSKE-W on cell viability in 3T3-L1 preadipocytes. Cells were treated with or without MSKE-W. Cell viability was measured 24 hours after treatment by Neutral Red methods. Values are the means \pm SD of four experiments.

\section{T3-L1 preadipocytes.}

To ascertain the inhibition of intracellular triglyceride accumulation in 3T3-L1 preadipocytes, we examined the effect of MSKE-W on the activity of Glycerol 2-phosphate dehydrogenase (GPDH), a key enzyme of triglyceride synthesis. Cultured 3T3-L1 preadipocytes were exposed to MSKE-W and then treated with a differentiation medium. As shown in Figure 2(c), treatment of 3T3-L1 preadipocytes with MSKE-W significantly inhibited GPDH activity in a dose-dependent manner.

\subsection{Effect of MSKE-W on Expression of Adipocyte-Specific Protein}

MSKE-W inhibits intracellular triglyceride accumulation and GPDH activity without cytotoxicity in 3T3-L1 adipocytes. Therefore, we examined the effect of MSKE$\mathrm{W}$ on the expression of adipogenesis factors in 3T3-L1 adipocytes. Adipocyte differentiation involves a series of programmed changes in adipogenic protein expression. To determine whether reduced lipid accumulation and GPDH activity by MSKE-W alter the differentiation program in cells, the expression of some adipogenic proteins was examined by Western blot analysis. As shown in Figure 3, MSKE-W reduced the protein levels of major adipogenic transcription factors, $\operatorname{PPAR} \gamma$ and $\operatorname{C} / \operatorname{EBP} \alpha$. MSKE-W dose-dependently reduced expression of these factors.

\subsection{Anti-Obesity Effect of a Diet Containing MSKE-W in Rats Fed an HFD}

To determine the effect of a diet containing MSKE-W in rats fed an HFD, we measured body weight gain and food intake for 42 days. As shown in Figure 4, rats fed a high fat-diet (HFD gained more weight than rats fed a normal diet (ND). Rats fed an HFD containing 1.0\% MSKE-W gained less weight than rats fed an HFD, although this trend was not significant. The amount of food intake was no different between rats fed an ND and rats
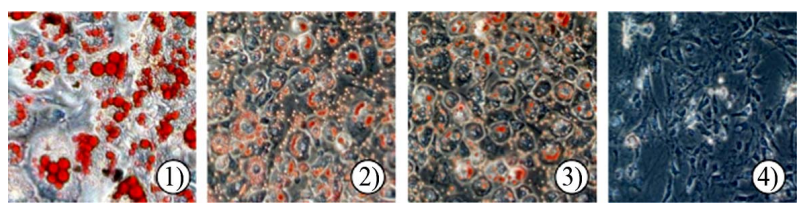

(a)

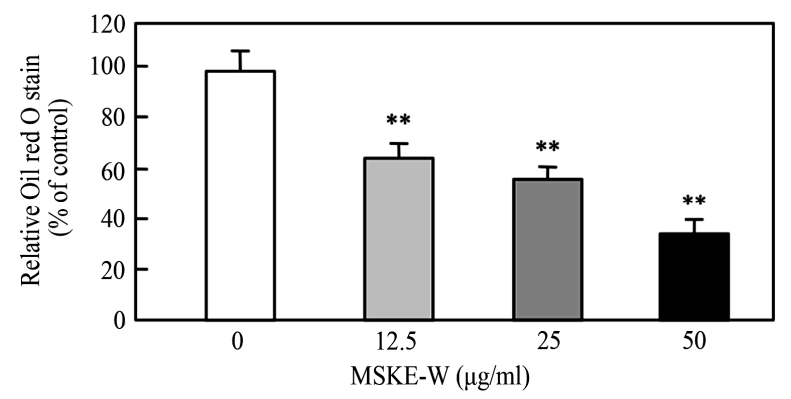

(b)

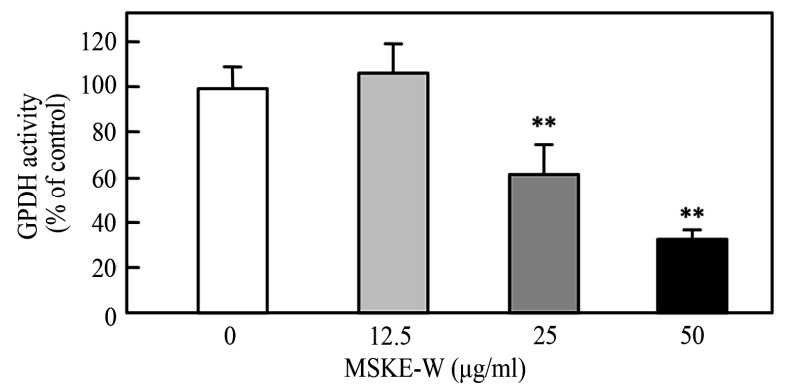

(c)

Figure 2. Effect of MSKE-W on Oil Red $\mathrm{O}$ staining and GPDH activity in cultured 3T3-L1 adipocytes. The 3T3-L1 adipocytes were cultured for 8 days after the initiation of differentiation with 0 - $50 \mu \mathrm{g} / \mathrm{ml}$ MSKE-W. (a) Photograph of Oil Red O stained cells: 1) $0 \mu \mathrm{g} / \mathrm{ml}$, 2) $12.5 \mu \mathrm{g} / \mathrm{ml}$, 3) $25 \mu \mathrm{g} / \mathrm{ml}$ and 4) $50 \mu \mathrm{g} / \mathrm{ml}$. (b) Oil Red O was extracted and its optical density was monitored spectrophotometrically at $510 \mathrm{~nm}$. (c) GPDH activities in cultured 3T3-L1 adipocytes. The results are presented as the mean $\pm \mathrm{SD}$ of four experiments. ${ }^{* *} p<$ 0.01 versus control cells.

fed an ND containing 1.0\% MSKE-W or between rats fed an HFD and rats fed an HFD containing 1.0\% MSKE-W.

To examine whether body weight gain in the MSKEW-treated group was related to decreased fat accumulation, the weight of visceral fat and size of epididymal adipocytes were examined (Table 2). At the end of 42 days, the visceral fat mass was higher in rats fed an HFD than in rats fed an ND. The visceral fat mass in rats fed an HFD containing 1.0\% MSKE-W tended to be lower than that in rats fed an HFD. Adipocyte size was reduced in rats fed an HFD containing 1.0\% MSKE-W (Figure 5(a)).

Obesity and diabetes are frequently associated with nonalcoholic steatohepatitis. Several researchers have shown that high fat diets lead to increased triglyceride accumulation in the liver and induced histopathological 


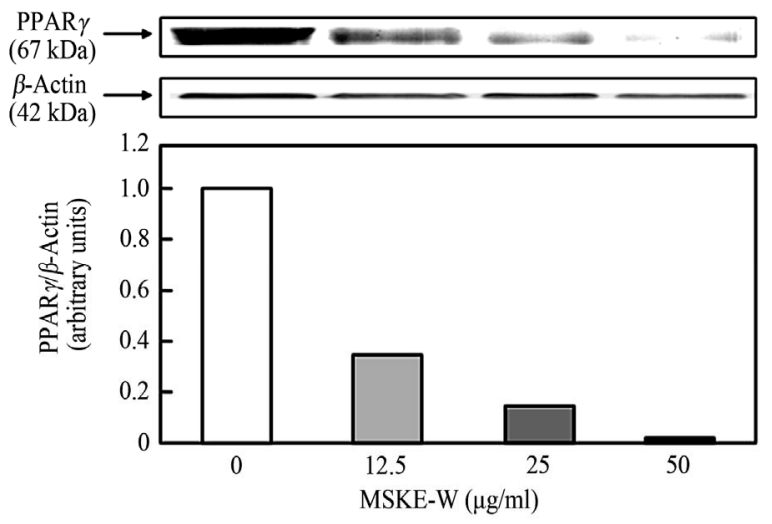

(a)
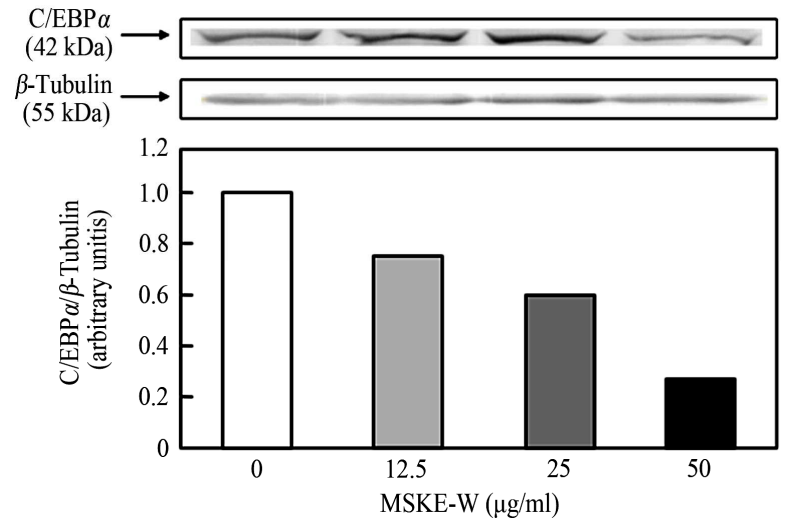

(b)

Figure 3. The effect of MSKE-W on PPAR $\beta$ and $\mathrm{C} / \mathrm{EBP} \alpha$ expression in cultured 3T3-L1 adipocytes. 3T3-L1 adipocytes were cultured for 2 days after the initiation of differentiation with $0-50 \mu \mathrm{g} / \mathrm{ml}$ MSKE-W. PPAR $\beta$ (a) and C/EBP $\alpha$ (b) protein levels were detected by Western blot. The PPAR $\beta$ and $\mathrm{C} / \mathrm{EBP} \alpha$ expression levels are expressed as a ratio to control levels. The results are representative of three separate determinations.

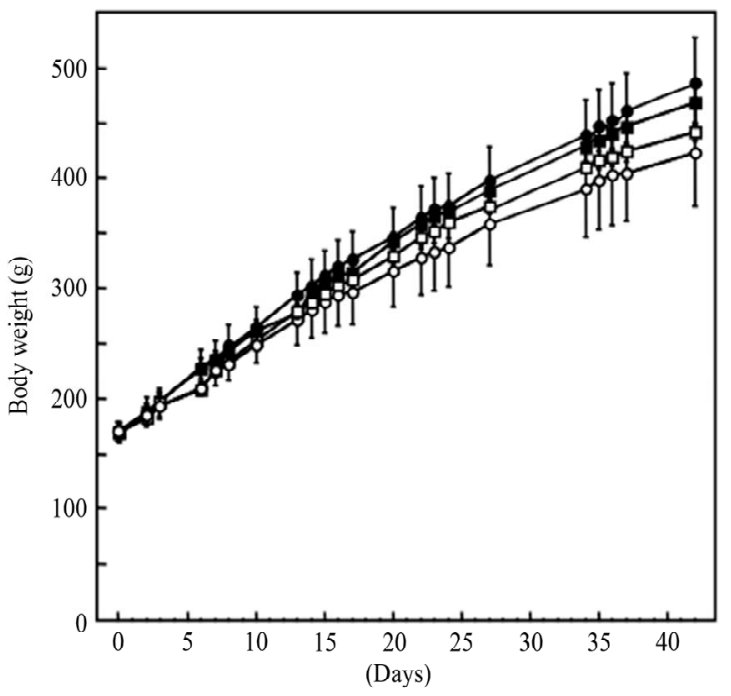

Figure 4. Changes in body weight. (०) ND ( $\square$ ) ND with $1 \% \operatorname{MSKE}-W(\bullet)$ HFD (घ) HFD with $1 \%$ MSKE-W.
Table 2. Changes in organ weight of high fat diet and MSKEW-treated rats.

\begin{tabular}{ccccc}
\hline \multirow{2}{*}{ Groups } & \multicolumn{4}{c}{ Organ weight $(\mathrm{g})$} \\
\cline { 2 - 5 } & Liver & Kidney & Spleen & Visceral fat \\
\hline ND & $12.4 \pm 2.5$ & $2.8 \pm 0.3$ & $1.0 \pm 0.2$ & $18.9 \pm 6.6^{\mathrm{a}}$ \\
ND $+1.0 \%$ & $12.6 \pm 0.7$ & $2.7 \pm 0.3$ & $1.0 \pm 0.1$ & $18.8 \pm 2.8^{\mathrm{a}}$ \\
MSKE-W & & & $0.9 \pm 0.1$ & $28.1 \pm 6.4^{\mathrm{b}}$ \\
HFD & $13.2 \pm 2.0$ & $2.8 \pm 0.5$ & & \\
HFD + 1.0\% & $13.0 \pm 2.0$ & $2.7 \pm 0.1$ & $0.9 \pm 0.1$ & $20.1 \pm 4.2^{\mathrm{ab}}$ \\
MSKE-W & & & \\
\hline Different letters $\left({ }^{\mathrm{a}}\right.$ and $\left.^{\mathrm{b}}\right)$ indicate significantly difference $(p<0.01)$.
\end{tabular}

features of human nonalcoholic steatohepatitis $[18,19]$. As shown in Figure 5(b), histological examination of rat livers fed an HFD showed steatohepatitis. However, rats fed an HFD containing 1.0\% MSKE-W showed no histopathological changes in liver tissue.

\section{DISCUSSION}

Mangoes (Mangifera indica L.) are one of the most important tropical foods. During mango processing, one of the main by-products is the seed. The seeds are not currently utilized for any commercial purpose and are discarded as a waste, becoming a source of pollution. Therefore, it is important to find an economically viable use for these wastes as food additives or supplements with high nutraceutical value.

Mangoes contain carotenoids and phenolic antioxidant compounds in the pulp, peel and seed. Matsusaka and Kawabata analyzed total polyphenol content and antioxidant activities of the non-edible portion (seed and peel) of eight tropical fruits and compared the edible parts. They determined that the antioxidant activities of non-edible portions were higher than those of the edible parts (pulp) and that the non-edible parts of mangoes had the highest radical scavenging capacity [20].

The extraction of polyphenols and antioxidants from the mango seed kernel are being studied. Dorta, et al. evaluated the effect of solvents (methanol, ethanol, acetone, water, methanol:water [1:1], ethanol:water [1:1] and acetone:water [1:1]) and temperature $\left(25^{\circ} \mathrm{C}, 50^{\circ} \mathrm{C}\right.$, $75^{\circ} \mathrm{C}$ ) on the efficiency of the extraction of antioxidants from the mango peel and seed. The solvents that obtained the best extraction of high antioxidant capacity in the $\beta$-carotene test, thiobarbituric acid reactive substances test and 2,2-diphenyl-1-picrylhydrazyl scavenging test were methanol, methanol: water, ethanol: water and acetone: water [21]. In our study, the powdered mango seed kernel was extracted with hot water. As shown in Figure 2 , the treatment of the extract dose-dependently decreased the accumulation of lipid droplets. The effect of extraction with hot water was lower than that of extract with ethanol:water or other organic solvents. However, 


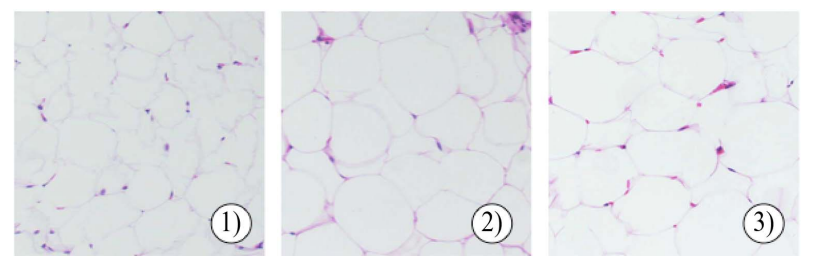

(a)

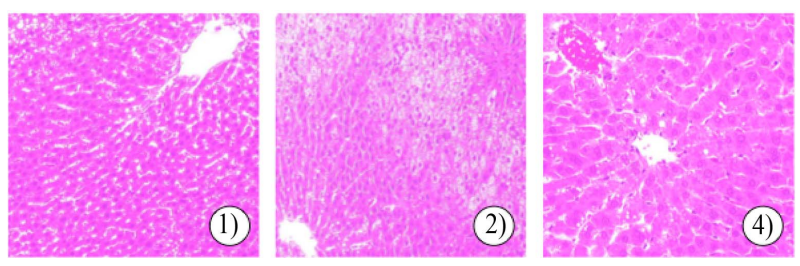

(b)

Figure 5. Effect of MSKE-W on morphological changes in adipose tissue (a) and the liver (b). Adipose tissue and liver sections were stained by HE: 1) ND, 2) HFD and 3) HFD with $1 \%$ MSKE-W.

hot water is a solvent that can be used in compliance with good manufacturing practices and is safely applicable by a human being. Therefore, the hot water extraction was used for this experiment.

There are several reports on the pharmacological properties of mangoes. Mango phytochemicals include compounds that have antioxidant, anti-inflammatory, immunomodulatory, chemo-preventive and anti-cancer activities [22].

Lucas, et al. examined the effects of dietary supplementation of $10 \%$ freeze-dried mango pulp on reduction of adiposity and alterations in glucose metabolism and the lipid profile in mice fed an HFD. They demonstrated that the incorporation of freeze-dried mango in the diet of mice improved glucose tolerance and lipid profile and reduced adiposity associated with a high-fat diet [23]. Pourahmad, et al. showed that aqueous extract of mango pulp effectively prevented all oxidative stress markers induced by cumene hydroperoxide, including cell lysate, ROS generation, lipid peroxidation, glutathione depletion, mitochondrial membrane potential decrease, lysosomal membrane oxidative damage and cellular proteolysis in freshly isolated rat hepatocytes. This finding suggests that the aqueous extract of mango pulp acts as a hepatoprotective and antioxidant agent against cumene hydroperoxide-induced hepatotoxicity [24]. Furthermore, Nithitanakool, et al. reported that the ethanol extract of the mango seed kernel has hepatoprotective potential against liver injury in rats induced by carbon tetrachloride. They also showed that the hepatoprotective effect of the ethanol extract is clearly supported by its polyphenolic nature of the main principal, 1.2,3,4,6-penta-O-galloyl-beta-Dglucopyranose, which exhibits potent antioxidant and anti-inflammatory activities [9]. Considering these studies, aqueous extract of mango and ethanol extract of mango have similar physiological effects, such as the hepatoprotective effect.

To the best of our knowledge, the results of this study demonstrate for the first time that mango seed kernel extract causes a significant decrease in the activity of GPDH in 3T3-L1 adipocytes without eliciting cytotoxicity. In addition, the extract inhibits cellular lipid accumulation through down-regulation of transcription factors such as PPAR $\gamma$ and $\mathrm{C} / \mathrm{EBP} \alpha$. The nuclear receptor PPAR $\gamma$ and members of $\mathrm{C} / \mathrm{EBP} \alpha$ synergistically activate downstream promoters of adipocyte-specific genes such as acetyl-CoA carboxylase, acyl-CoA synthase and GPDH. In adipocytes which express high levels of PPAR $\gamma$, expression of cytosolic GPDH is enhanced by PPAR $\gamma$. The in vitro anti-obesity ability of MSKE-W was checked using an in vivo diet-induced obesity rat model, and we found that MSKE-W treatment suppressed steatohepatitis induced by an HFD.

Lucas, et al. showed that dietary supplementation of $10 \%$ freeze-dried mango pulp reduced adiposity and alterations in glucose metabolism and the lipid profile in mice fed a high-fat diet [23]. In this study, we found that the visceral fat mass in rats fed an HFD containing $1.0 \%$ MSKE-W tended to be lower than that in rats fed an HFD, and adipocyte size was reduced in rats fed an HFD containing 1.0\% MSKE-W. Furthermore, histological liver examination of rats fed an HFD showed steatohepatitis. However, rats fed an HFD containing 1.0\% MSKE$\mathrm{W}$ showed no histopathological changes in liver tissue.

These results suggest that the content of the active compounds for anti-obesity in the seed kernel is higher than those in pulp. Additional research is required to characterize the active compounds in MSKE-W.

In conclusion, we report that MSKE-W exerts antiobesity action both in vivo and in vitro. Although the precise mechanisms need to be further elucidated, MSKE-W provides novel preventive potential against obesity and other metabolic diseases.

\section{ACKNOWLEDGEMENTS}

We thank to Mr. Yasumitsu Akhoshi, a pathologist of Kinki University Life Science Research Institute, for assistance of histological analysis. This study was partially supported by a Grant-in Aid for Scientific Research from the Japan Society for the Promotion of Science (24500987) and the Science and Technology Commons from the Japan Science and Technology Agency.

\section{REFERENCES}

[1] Kiess, W., Prezold, S., Topfer, M., et al. (2008) Adipocytes and adipose tissue. Best Practice \& Research. Clinical Endocrinology Metabolism, 22, 135-153. doi:10.1016/j.beem.2007.10.002

[2] Shimomura, I., Funahashi, T., Takahashi, M., et al. (1996) 
Enhanced expression f PAI-1 in visceral fat: Possible contributor to vascular disease in obesity. Nature Medicine, 2, 800-803. doi: $10.1038 / \mathrm{nm} 0796-800$

[3] Nawrocki, A.R. and Scherer, P.E. (2005) Keynote review: The adipocyte as Gdiscoverytarget. Drug Discovery Today, 10, 1219-1230. doi:10.1016/S1359-6446(05)03569-5

[4] Farmer, S.R. (2006) Transcriptional control of adipocytes formation. Cell Metabolism, 4, 263-273. doi:10.1016/j.cmet.2006.07.001

[5] Rosen, E.D. and MacDougald, O.A. (2006) Adipocyte differentiation from the inside out. Nature Reviews. Molecular Cell Biology, 7, 885-896. doi:10.1038/nrm2066

[6] Berardin, N., Knodler, M., Schieber, A., et al. (2005) Utilization of mango peels as a source of pectin and polyphenolics. Innovative Food Science \& Emerging Technologies, 6, 441-452.

[7] Maharram, Y. and Moustafa, A.M. (1982) Utilization of mango seed kernel (Magifera indica L.) as a source of oil. Food Chemistry, 8, 269-276. doi:10.1016/0308-8146(82)90029-2

[8] Berreto, J.C,, Trevisan, M.T.S., Hull, W.E., et al. (2008) Characterization and quantitation of polyphenolic compounds in bark, kernel, leaves, and peel of mango (Mangifera indica L.). Journal of Agricultural and Food Chemistry, 56, 5599-5610. doi:10.1021/jf800738r

[9] Nithitanakool, S., Pithayanukul, P. and Bavovada, R. (2009a) Antioxidant and hepatoprotective activities of Thai mango seed kernel extract. Plant Medica, 75, 11181123. doi:10.1055/s-0029-1185507

[10] Nithitanakool, S., Pithayanukul, P. and Bavovada, R. (2009b) Molecular docking studies and anti-tyrosinase activity of Thai mango seed kernel extract. Molecules, 14, 257-265. doi:10.3390/molecules 14010257

[11] Leanpolchareanchai, J., Pithayanukul, P., Bovovada, R. and Saparpakorn, P. (2009) Molecular docking studies and anti-enzymatic activities of Thai mango seed kernel extract against snake venoms. Molecules, 14, 1404-1422. doi:10.3390/molecules 14041404

[12] Pithayanukul, P., Leanpolchareanchai, J. and Saparpakorn, P. (2009) Molecular docking studies and anti-snake venom metalloproteinase activity of Thai mango seed kernel extract. Molecules, 14, 3198-3213. doi:10.3390/molecules 14093198

[13] Riddell, R.J., Clothier, R.H. and Balls, M. (1986) An evaluation of three in vitro cytotoxicity assays. Food and Chemical Toxicology, 24, 467-471. doi:10.1016/0278-6915(86)90095-5

[14] Huang, X., Kojima-Yuasa, A., Norikura, T., et al. (2007) Mechanism of anti-cancer activity of Ziziphus jujube in
HepG2 cells. The American Journal of Chinese Medicine, 35, 517-532. doi:10.1142/S0192415X0700503X

[15] Fotakis, G. and Timbrell, J.A. (2006) In vitro cytotoxicity assays: comparison of LDH, neutral red, MTT and protein assay in hepatoma cell lines following exposure to cadmium chloride. Toxicology Letters, 160, 171-177. doi:10.1016/j.toxlet.2005.07.001

[16] Ramirez-Zacarias, J.L., Castro-Monozledo, F. and KuriHarcuch, W. (1992) Quantitation of adipose conversion and triglycerides by staining intracytoplasmic lipids with oil red O. Histochemistry, 97, 493-497. doi:10.1007/BF00316069

[17] Wise, L.S. and Green, H. (1979) Participation of one isozyme of cytosolic glycerophosphate dehydrogenase in the adipose conversion of 3T3 cells. The Journal of Biological Chemistry, 254, 273-275.

[18] Sundaresan, S. Vijayagopal, P., Mills, N., et al. (2011) A mouse model for nonalcoholic steatohepatitis. The Journal of Nutritional Biochemistry, 22, 979-984. doi:10.1016/j.jnutbio.2010.08.011

[19] Lieber, C.S,, Leo, M.A., Mak, K.M., et al. (2004) Model of nonalcoholic steatihepatitis. The American Journal of Clinical Nutrition, 79, 502-509.

[20] Matsusaka, Y. and Kawabata, J. (2010) Evaluation of antioxidant capacity of non-edible parts of some selected tropical fruits. Food Science and Technology Research, 16, 467-472. doi:10.3136/fstr.16.467

[21] Dorta, E., Lobo, M.G. and Gonzalez, M. (2012) Reutilization of mango byproducts: Study of the effect of extraction solvent and temperature on their antioxidant properties. Journal of Food Science, 77, C80-C88. doi:10.1111/j.1750-3841.2011.02477.x

[22] Masibo, M. and He, Q. (2009) Mango bioactive compounds and related nutraceutical properties. Food Reviews International, 25, 346-370. doi:10.1080/87559120903153524

[23] Lucas, E.A., Li, W.J., Peterson, S.K., Brown, A., et al. (2011) Mango modulates body fat and plasma glucose and lipids in mice fed a high-fat diet. The British Journal of Nutrition, 106, 1495-1505. doi:10.1017/S0007114511002066

[24] Pourahmad, J., Eskandari, M.R., Shakibaei, R. and Kamalinejad, M. (2010) A search for hepatoprotective activity of fruit extract of Mangifera indica L. against oxidative stress cytotoxicity. Plant Foods for Human Nutrition, 65, 83-89. doi:10.1007/s11130-010-0161-9

[25] Patsouris, D., Mandard, S., Voshol, P.J., et al. (2004) PPAR governs glycerol metabolism. The Journal of Clinical Investgation, 114, 94-103. 